UDC 347.965.6

LBC 67.75

\title{
THE FORMATION OF THE LEGAL PROFESSION IN UKRAINE: THE PERIODS OF KIEVAN RUS AND THE POLISH-LITHUANIAN REIGN
}

\author{
Victor V. Zaborovskiy \\ Uzhgorod National University, Uzhgorod, Ukraine
}

\begin{abstract}
Introduction: the author in the article investigates the formation of Ukrainian legal profession in the days of Kievan Rus in the period of the Polish-Lithuanian rule. Methods used scientific methods of research, such as analysis, synthesis, comparison, and private research methods: formal-legal, technical and legal. Much attention is paid to the historical and legal research methods. Results: the author analyzes the formation stage of the legal profession in the times of Kievan Rus, in particular on the basis of the study the provisions of Article of the Grand Duchy of Lithuania (in all its editions of 1529, 1566 and 1588), relating to the activities and the Deputy Procurator. Conclusions: it is concluded that the institution of Ukrainian Lawyer Association was born in the times of Kievan Rus, but is already becoming a professional advocacy in Ukraine takes place during the Polish-Lithuanian rule. It is pointed out that according to the Statute of the Grand Duchy of Lithuania, in particular the third edition in 1588, the profession of procurator acquires the features of a professional activity, which indicates the origin of the legal profession is already a professional in Ukraine, but not its organizational design.
\end{abstract}

Keywords: lawyer, lawyer activity, the development of Ukrainian institute of advocacy, Kyiv Rus, during the Polish-Lithuanian government, the procurator.

УДК 347.965 .6

ББК 67.75

\section{СТАНОВЛЕНИЕ АДВОКАТУРЫ НА ТЕРРИТОРИИ УКРАИНЫ: ПЕРИОДЫ КИЕВСКОЙ РУСИ И ПОЛЬСКО-ЛИТОВСКОГО ПРАВЛЕНИЯ}

\author{
Виктор Викторович Заборовский \\ Ужгородский национальный университет, г. Ужгород, Украина
}

\begin{abstract}
Введение: в статье автором исследуется становление института украинской адвокатуры во времена Киевской Руси и в период польско-литовского правления. Методы: использованы общенаучные методы исследования, такие как анализ, синтез, сравнение, а также частнонаучные методы исследования: формально-юридический, технико-юридический. Большое внимание уделяется историко-правовому методу научного исследования. Результаты: автор анализирует этап становления института адвокатуры во времена Киевской Руси, в

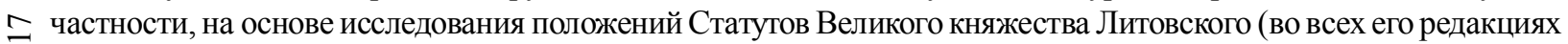
1529, 1566 и 1588 гг.), касающихся деятельности заместителя и прокуратора. Выводы: делается вывод о том, что ضं институт украинской адвокатуры зародился еще во времена Киевской Руси, но становление профессиональضे ной адвокатуры в Украине происходило уже в период польско-литовского правления. Указывается на то, что согласно Статутам Великого княжества Литовского, в частности третьей редакции 1588 г., профессия прокуратора приобретала черты профессиональной деятельности, а это свидетельствует о зарождении уже профессио 의 оньнй адвокатуры в Украине, но еще не о ее организационном оформлении.

Ключевые слова: адвокат, адвокатская деятельность, становление украинской адвокатуры, Киевская Русь, период польско-литовского правления, прокуратор.
\end{abstract}




\section{ТЕОРИЯ И ПРАКТИКА ГОСУДАРСТВЕННО-ПРАВОВОГО РАЗВИТИЯ}

\section{Введение}

В статье 1 Конституции Украины указано, что Украина это суверенное, независимое, демократическое, социальное и правовое государство. Одним из основных признаков, которые указывают на существование правового государства, является создание государственного механизма, который имеет реальную возможность обеспечить права, свободы и законные интересы человека. Главным элементом такого механизма, без сомнения, является адвокатура, уровень развития которой в цивилизованном мире рассматривается как индикатор демократии в обществе, поскольку она являет собой ключевую фигуру в предоставлении правовой помощи всем без исключения лицам. Среди актуальных и дискуссионных вопросов в сфере деятельности такого института гражданского общества, как адвокатура, можно назвать проблему ее происхождения. В данном аспекте не менее актуальным остается вопрос о происхождении института украинской адвокатуры.

\section{Обсуждение результатов}

В юридической литературе имеются различные подходы относительно происхождения адвокатуры. Так, некоторые ученые исходят из того, что «адвокатура - древнейший и в то же время общечеловеческий институт» [8, c. 6]. К такому выводу приходит А.Г. Кучерена, считая при этом, что адвокатура «существовала во все времена и у всех народов» [5, c. 16]. Противоположной точки зрения придерживается, в частности, Е.В. Васьковский, который на основании анализа работы А.Н. Стоянова «История адвокатуры» [14] указывает на то, что «проходили тысячелетия, разрастались сильные цивилизации из зачатков патриархального быта; издавались законы, устраивались суды, писались книги о правоведении и управлении государством, но не учреждались адвокаты» [2, с. 9].

В данном случае заслуживает внимания позиция И.С. Яртиха, который указывает на то, что «адвокатура в современном понимании этого явления возникла как публично-государственный институт в древнем Риме в период расцвета первой римской республики, торжества прав и закона. Адвокатура стала тем институтом, без которого, по мнению общества и государства, невозможно осуществление справедливого судопроизводства» [17, с. 315]. Разделяя позицию И.С. Яртиха, мы обращаем внимание на то, что «безусловно, институты Древнего Рима и Древней Греции лишь отдаленно напоминали то, что принято в современном мире именовать институтом адвокатуры» [8, с. 7], но неоценим вклад данного периода зарождения адвокатуры в дальнейшее формирование института адвокатуры в странах не только Западной, но и Восточной Европы.

Относительно происхождения института украинской адвокатуры мы согласны с позицией О.В. Синеокого, который указывает на то, что ее прообраз «зародился еще во времена Киевской Руси (IX-XII вв.), когда роль защитников в суде выполняли родные и друзья сторон, «послухи» (свидетели обвиняемого), «видоки» (свидетели совершенного стороной или спорного факта). На этом этапе судопроизводство характеризовалось сплошным господством обычного права и полным его преимуществом над писаным законом, работа защитника в судах имела характер общественного, товарищеского, а не профессионального занятия» [7, с. 57]. Таких же позиций придерживаются и П.В. Кучевский, Р.А. Чайка, которые отмечают, что «первым шагом в формировании данного института права и основанием для организации профессиональных защитников было судебное представительство, которое сложилось во времена Киевской Руси, в том числе активная помощь в этом процессе родственников “сутяжников" и их "суседей”, “миру” и т. д.» [4, с. 8; 15, с. 9]. Следует отметить, что в этот период была проведена систематизация правовых норм, и правовой анализ положений Русской Правды (важнейшего законодательного памятника Древней Руси) позволяет говорить о проведенной систематизации, так как данный документ не просто беспорядочный сборник правовых обычаев без общего начала, а именно унифицированный кодифицированный акт [3, с. 14].

Несколько иной позиции придерживается О.Г. Яновская, которая обращает внимание на то, что «в Украине, как и в других славянских государствах, адвокатура существо- 
вала довольно длительное время, но не в виде самостоятельной профессии, а в связи с судебным представительством, что сначала допускалось только в виде исключения для некоторых категорий лиц (детей, женщин, стариков, монахов, глухих) и получило впоследствии свободное применение, превратившись в профессиональное занятие особого класса лиц, которые, будучи лучше других знакомы с нормами права и процесса, стали в то же время выполнять роль и правозаступников» [16, c. 16]. В дальнейшем она делает вывод, что профессиональная адвокатура в Украине сформировалась в период польско-литовского правления (XIV-XVI вв.). Такой же точки зрения придерживается и В.А. Святоцкая, которая, исследуя вопрос о становлении и развитии института адвокатуры, отмечает, что «первые зародыши сословной профессиональной адвокатуры на украинских землях появляются во время пребывания в составе Великого княжества Литовского и Польского королевства (XIV-XVII вв.). В этот период обычное право вытесняется писаным законом в городах и общегосударственных судах, где вводится магдебургское (немецкое городское) право (XV в.). Дело судебной защиты в городских и общегосударственных судах этого времени приобретает профессиональный характер. Во времена польско-литовского периода на первый план в качестве защитника выступает прокуратор» [7, с. 10].

Мы разделяем позицию авторов о том, что формирование на Украине адвокатуры, которая приобретает черты профессионального характера, происходит во времена польсколитовского правления (XIV-XVI вв.). Такой вывод нам позволяет сделать анализ положений Статутов Великого княжества Литовского (во всех редакциях 1529, 1566 и 1588 гг.), которые действовали на украинских землях до 1840 г. (на территории Киевской, Подольской и Волынской губерний) и 1843 г. (на Левобережной Украине).

Так, в первом Статуте Великого княжества Литовского (1529 г.) применяются термины «заместители» и «прокураторы». О заместителях, в частности, речь идет в арт. 8 (о замене в процессе одного лица другим), в то время как арт. 9 (о прокураторе) Раздела 6 (О судьях) [11, с. 246] применяется соответ- ственно другой термин. Что касается разграничения указанных терминов, то заслуживает внимания мнение М.Р. Аракеляна, который указывает на «отсутствие четких границ между “заместителем” (арт. 8) и “прокуратором" (арт. 9). Только при тщательном анализе указанных артикулов и судебных дел можно усмотреть эту границу: услугами первого пользовались родственники, больные и немощные люди, услугами другого - состоятельные шляхтичи. Такая нечеткость в регламентации правового статуса прокуратора не определяет и его ответственности за проигранное дело. Однако эта ответственность прослеживается в запрете быть прокуратором лицу, которое не имеет оседлости, то есть земельных владений в Великом княжестве Литовском, и с которого, в случае проигрыша дела, ничего взыскать» [1, с. 105]. Мы фактически разделяем позицию ученого о том, что эта норма дает основание говорить о прокураторе как специалисте, для которого покровительство стало профессией и услуги которого стали платными, то есть речь идет фактически об адвокате в современном его понимании.

Во втором Статуте Великого княжества Литовского (1566 г.) судебному представительству посвящены артикулы 31-37 Раздела 4 (О судьях и о судах). Анализ указанных артикулов дает возможность прийти к выводу, что в Статуте 1566 г. уже достаточно четко разграничены статусы заместителя как уполномоченного лица ответчика в суде и прокуратора (профессионального представителя лица). Так, в арт. 32 Раздела 4 Статута 1566 г. отмечалось, что «если бы кто по искам или на котором году припавшего не мог на суде быть, как с болезнью, так и по другим некоторым причинам и потребностями своими; тогда прокуратора или уполномоченного своего может вместо себя в деле иметь» [12, с. 311]. В то же время в арт. 33 этого же раздела указывалось на то, что «если кто не будучи в состоянии сам вести дело свое в суде и не умея молвить, прокуратора требовал тогда суд должен ему из вряда прокуратора дать и приказать прокуратору от его имени молвить и дело его вести» [12, с. 312].

Что касается третьего Статута Великого княжества Литовского (1588 г.), то ученые 
характеризуют его как наиболее «систематизированный закон, по которому жило государство периода литовско-русского правления» [6, c. 11], и как таковой он «наиболее подробно устанавливает порядок судебной защиты» $[16$, c. 16]. Институту судебного представительства было посвящено пять артикулов (арт. 5561) Раздела IV (О судах и о судьях) Статута [13, с. 162-167]. В частности, в арт. 56 шла речь о необходимости получения письменного поручения на ведение дела прокуратором, которое определяло пределы его полномочий, за исключением личного присутствия стороны (арт. 57). Артикул 58 предусматривал ряд требований, которым должен соответствовать прокуратор. По нашему мнению, наиболее прогрессивным артикулом данного Устава был арт. 57, который закреплял норму об обязательном назначении прокуратора малоимущим и сиротам (к тому же, где бы кто не мог и не умел сам сказать и дела свои в суде вести, а через убожество и нужды свои прокуратора сам себе нанять не мог, как вдовы и сироты, и просили бы вряд о прокураторе, тогда вряд должен такого прокуратора даром предоставить и приказать от них в суде отвечать, и прокуратор имеет в том вряда послушаться) [13, с. 164]. Учитывая указанное, можно прийти к выводу, что деятельность прокуратора уже приобретает вид самостоятельной профессии, а это свидетельствует о зарождении профессиональной адвокатуры, но еще ни в коем случае не о ее организационном оформлении.

\section{Выводы}

Учитывая указанное, можно прийти к выводу, что институт украинской адвокатуры зародился еще во времена Киевской Руси. Но в этот период деятельность защитника еще не содержит признаков профессионального характера. Зарождение профессиональной адвокатуры в Украине происходит на более позднем этапе ее становления, а именно в период польско-литовского правления. Согласно Статутам Великого княжества Литовского, в частности третьей редакции 1588 г., профессия прокуратора приобретает черты профессиональной деятельности, а это свидетельствует о зарождении уже профес- сиональной адвокатуры в Украине, но еще не о ее организационном оформлении. Следует отметить и то, что в это время использовался и термин «адвокат», но он имел совсем другое значение, поскольку касался должностного лица - «старосты», на которого фактически возлагалось осуществление судебной власти в городе.

\section{СПИСОК ЛИТЕРАТУРЫ}

1. Аракелян, М. Р. Развитие института судебного представительства в Великом княжестве Литовском / М. Р. Аракелян // Наукові праці Одеської національної юридичної академії. - 2009. - T. VIII. C. 101-109.

2. Васьковский, Е. В. Организация адвокатуры. В 2 ч. Ч. 1. Очерк всеобщей истории адвокатуры / Е. В. Васьковский. - Спб. : Н. К. Мартынов, 1893. $-621 \mathrm{c}$.

3. Иншакова, А. О. Русская правда как первоисточник унифицированного гражданско-правового развития Русского государства / А. О. Иншакова // Вестник Волгоградского государственного университета. Серия 5, Юриспруденция. - 2015. - № 4 (29). - C. 10-18.

4. Кучевський, П.В.Діяльність адвоката у кримінальному процесі : автореф. дис. ... канд. юрид. наук / Кучевський Петро Васильович. - К., 2011. $18 \mathrm{c}$.

5. Кучерена, А. Г. Роль адвокатуры в становлении гражданского общества в России : автореф. дис. ... д-ра юрид. наук / Кучерена Анатолий Григорьевич. - М., 2002. - 44 с.

6. Сафулько, С. Ф. Енциклопедичний довідник майбутнього адвоката. У 2 ч. Ч. 1 / О. Д. Святоцький, Т. Г. Захарченко, С. Ф. Сафулько. -К. : Ін Юре, 2008. -616 c.

7. Святоцька, В. О. Інститут адвокатури України: становлення та розвиток : автореф. дис. ... канд. юрид. наук / Святоцька Вікторія Олександрівна. Л., 2010. -20 c.

8. Святоцький, О. Д. Адвокатура: історія і сучасність / О. Д. Святоцький, В. В. Медведчук. - К. : Ін Юре, 1997. - 320 с.

9. Синеокий, О. В. Адвокатура как институт правовой помощи и защиты / О. В. Синеокий. $-\mathrm{X}$ : Право, 2008. -496 с.

10. Смирнов, В. Н. Адвокатура и адвокатская деятельность / В. Н. Смирнов, А. С. Смыкалин. М. : Проспект ; Екатеринбург : Уральская государственная юридическая академия, 2011. - $314 \mathrm{c}$.

11. Статути Великого князівства Литовського. У 3 т. Т. І. Статут Великого князівства Литовського 1529 року / за ред. С. Ківалова, П. Музиченка, 
А. Панькова. - Одеса : Юридична література, 2003. $464 \mathrm{c}$.

12. Статути Великого князівства Литовського. У 3 т. Т. II. Статут Великого князівства Литовського 1566 року / за ред. С. В. Ківалова, П. П. Музиченка, А. Панькова. - Одеса : Юридична література, 2003. $560 \mathrm{c}$.

13. Статути Великого князівства Литовського. У 3 т. Т. ІІІ. Статут Великого князівства Литовського 1588 року / за ред. С. Ківалова, П. Музиченка, А. Панькова. - Одеса : Юридична література, 2003. $568 \mathrm{c}$.

14. Стоянов, А. История адвокатуры / А. Стоянов. - Х. : Унив. тип., 1869. - Вып. 1: Египет, Индия, евреи, греки, римляне. $-146 \mathrm{c.}$

15. Чайка, Р. А. Участь захисника на досудовому слідстві : автореф. дис. ... канд. юрид. наук / Чайка Роман Анатолійович. - Х., 2008. - 19 с.

16. Яновська, О. Г. Адвокатура України / О. Г. Яновська. - К. : Юрінком Інтер, 2007. - 280 с.

17. Яртых, И. С. Адвокатура и гражданское общество / И. С. Яртых. - Ульяновск : Печатный двор, 2007. - 336 с.

\section{REFERENCES}

1. Arakelyan M.R. Razvitie instituta sudebnogo predstavitelstva v Velikom knyazhestve Litovskom [Development of Institute of Legal Representation in the Grand Duchy of Lithuania]. Naukovi pratsi Odeskö̈ natsionalnö̈ yuridichnö akademiï [Proceedings of Odessa National Law Academy], 2009, no. VIII, pp. 101-109.

2. Vaskovskiy E.V. Organizatsiya advokatury. $V 2$ ch. Ch. 1. Ocherk vseobshchey istorii advokatury [The Organization of the Bar. In 2 Parts. Part 1. Outline of World History of the Bar]. Saint Petersburg, N.K. Martynov Publ., 1893. 621 p.

3. Inshakova A.O. Russkaya pravda kak pervoistochnik unifitsirovannogo grazhdanskopravovogo razvitiya Russkogo gosudarstva [Russkaya Pravda as a Primary Source of Unified Civil and Legal Development of Russian State]. Vestnik Volgogradskogo gosudarstvennogo universiteta. Seriya 5, Yurisprudentsiya [Science Journal of Volgograd State University. Jurisprudence], 2015, no. 4 (29), pp. 10-18.

4. Kuchevskiy P.V. Diyalnist advokata $u$ kriminalnomu protsesi: avtoref. dis. ... kand. yurid. nauk [Business Lawyer in Criminal Proceedings. Cand. jurid. sci. abs. diss.]. Kyiv, 2011. 18 p.

5. Kucherena A.G. Rol advokatury v stanovlenii grazhdanskogo obshchestva v Rossii: avtoref. dis. ... d-ra yurid. nauk [The Role of Advocacy in the Development of Civil Society in Russia. Dr. jurid. sci. abs. diss.]. Moscow, 2002. 44 p.

6. Safulko S.F., ed. Entsiklopedichniy dovidnik maybutnogo advokata: 42 ch. [Collegiate Guide Future Lawyer. In 2 vols. Vol. 1]. Kyiv, In Jure Publ., 2008. 616 p.

7. Svyatocka V.O. Institut advokaturi Ukraïni: stanovlennya ta rozvitok: avtoref. dis. ... kand. yurid. nauk [Institute of Advocacy of Ukraine: Formation and Development. Cand. jurid. sci. abs. diss.]. Lviv, 2010.20 p.

8. Svyatockiy O.D., Medvedchuk V.V. Advokatura: istoriya i suchasnist [Advocacy: History and the Present]. Kyiv, In Jure Publ., 1997. 320 p.

9. Sineokiy O.V. Advokatura kak institut pravovoy pomoshchi $i$ zashchity [Advocacy as an Institute of Legal Assistance and Protection]. Kharkiv, Pravo Publ., 2008. 496 p.

10. Smirnov V.N., Smykalin A.S. Advokatura $i$ advokatskaya deyatelnost [Advocacy and Legal Practice]. Moscow, Prospectus Publ.; Ekaterinburg, Ural State Law Academy Publ., 2011. 314 p.

11. Kivalov S.V., Muzichenko P.P., Pankov A., eds. Statuti Velikogo knyazivstva Litovskogo. U 3 t. T. 1 . Statut Velikogo knyazivstva Litovskogo 1529 roku [Statute of the Grand Duchy of Lithuania: in 3 vols. Vol. 1. Statute of the Grand Duchy of Lithuania in 1529]. Odessa, Law books Publ., 2003. 464 p.

12. Kivalov S.V., Muzichenko P.P., Pankov A., eds. Statuti Velikogo knyazivstva Litovskogo. U 3 t. T. 2. Statut Velikogo knyazivstva Litovskogo 1566 roku [Statute of the Grand Duchy of Lithuania. In 3 vols. Vol. 2. Statute of the Grand Duchy of Lithuania in 1566]. Odessa, Law books Publ., 2003. 560 p.

13. Kivalov S.V., Muzichenko P.P., Pankov A., eds. Statuti Velikogo knyazivstva Litovskogo. U 3 t. T. 3. Statut Velikogo knyazivstva Litovskogo 1588 roku [Statute of the Grand Duchy of Lithuania: in 3 vols. Vol. 3. Statute of the Grand Duchy of Lithuania in 1588]. Odessa, Law books, 2003. 568 p.

14. Stoyanov A. Istoriya advokatury. V 2 vyp. Vyp. 1. Egipet, Indiya, evrei, greki, rimlyane [History of the Bar. In 2 vols. Vol. 1.: Egypt, India, Jews, Greeks, Romans]. Kharkiv, Univ. type Publ., 1869. 146 p.

15. Chayka R.A. Uchast zahisnika na dosudovomu slidstvi: avtoref. dis. ... kand. yurid. nauk [A Lawyer in Pre-Trial Investigation. Cand. jurid. sci. abs. diss.]. Kharkiv, 2008. 19 p.

16. Janovska O. G. Advokatura Ukraïni [Bar Ukraine]. Kyiv, Yurinkom Inter Publ., 2007. 280 p.

17. Jartyh I.S. Advokatura i grazhdanskoe obshchestvo [Advocacy and Civil Society]. Ulyanovsk, Printing House Publ., 2007. 336 p. 


\section{ТЕОРИЯ И ПРАКТИКА ГОСУДАРСТВЕННО-ПРАВОВОГО РАЗВИТИЯ}

\section{Information About the Author}

Victor V. Zaborovskiy, Candidate of Juridical Sciences, Associate Professor, Assistant Professor, the Department of Civil Law, Uzhgorod National University, Lawyer, Kapitulnaya St., 26, 88000 Uzhgorod, Ukraine, zaborovskyviktor@rambler.ru.

\section{Информация об авторе}

Виктор Викторович Заборовский, кандидат юридических наук, доцент, доцент кафедры гражданского права, Ужгородский национальный университет, адвокат, ул. Капитульная, 26, 88000 г. Ужгород, Украина, zaborovskyviktor@rambler.ru. 